\title{
Intraempreendedorismo e a inovação na gestão pública federal
}

\author{
Meire Lúcia Gomes Monteiro Mota Coelho
}

\section{Introdução}

Nas organizações, sejam públicas ou privadas, com ou sem fins lucrativos, o agente da inovação é o empreendedor. Ele busca e conduz a inovação. Joseph Schumpeter associou pioneiramente a inovação ao empreendedorismo como processo que o permeia nas suas mais diversas formas e meios sem, no entanto, confundi-lo ou mesmo suplantá-lo. O empreendedor impulsiona o capital pois traz em si "a força destruidora e criativa" de novos mercados, produtos e serviços (SCHUMPETER, 1949).

Joseph Schumpeter não só sustentou as bases do empreendedorismo na teoria econômica, como introduziu, no seu estudo "Economic Theory and Entrepreneurial History" (1949), o Estado como agente do processo de inovação, destacando as contribuições do Departamento de Agricultura dos Estados Unidos como vetor inovador. Para ele, o fenômeno da inovação é institucional e pode ocorrer em qualquer lugar, seja qual for o processo, momento, meio ou posição nas organizações, sejam públicas ou privadas. 
De forma geral, o empreendedorismo é comum tanto no universo das organizações públicas quanto no das privadas. As organizações públicas são semelhantes às demais; no entanto, possuem características próprias (rotinas, hierarquia excessiva, descontinuidade, paternalismo etc) que constituem verdadeiros obstáculos às inovações e mudanças e que se opõem ao empreendedorismo (DRUCKER, 2008;PIRES \& MACEDO, 2006; THOENIG, 2007; DAL'BÓ, 2008).

O empreendedorismo, no âmbito das organizações públicas, permeado por caracteres muito peculiares e próprios, é um fenômeno multifacetado e complexo. Como se dá o intraempreendedorismo nas organizações públicas? Quais as dificuldades? Quais as soluções adotadas?

Ações empreendedoras tiveram lugar em nossos quinhentos anos de história, desde a implantação das feitorias destinadas à exploração da madeira, passando pelo ciclo nordestino da cana e pelo ciclo do ouro; sem contar, por exemplo, a obstinação de um Osvaldo Cruz em exterminar doenças tropicais no Rio de Janeiro, de um Marechal Rondon na árdua tarefa de conquistar o Oeste do Brasil; ou aquelas que levaram o país de dependente crônico do petróleo a potência no setor. É possível fomentar um ambiente empreendedor mesmo em um cenário em que a burocracia é predominante, como é o caso das organizações públicas?

O objetivo deste artigo é apresentar três ações empreendedoras em organizações públicas, premiadas pela ENAP no concurso Inovação na Gestão Pública Federal. A partir da revisão de literatura e estudo de caso, serão confrontados os diversos tipos e modelos de processos de inovação, para identificar as dificuldades apontadas e quais as soluções adotadas nas ações premiadas pelo concurso. Foram selecionados três casos de iniciativas inovadoras no Instituto Nacional do Seguro Social (INSS), apontando a origem, características, amplitude e o modelo do processo de inovação. Nosso quadro teórico de referência está estruturado no sentido de aprofundar nossa percepção, bem como nos dar condições de comparar alguns estudos e apontar lacunas, se existentes.

\section{Revisão de literatura}

\section{Inovação e empreendedorismo}

Não se pode falar em inovação sem falar em empreendedorismo. Inovar traz implícito a ideia de empreender. Desde o século XVII, nos primórdios de sua formulação por Richard Cantillon e Jean Baptiste Say, a inovação vem associada ao empreendedorismo. Richard Cantillon considerava os empreendedores verdadeiros aventureiros, que "corriam riscos visando o lucro". O segundo, chamado o "pai do empreendedorismo", iniciou a sua teorização e a relacionava às mudanças e à inovação (VOGEL, 2004).

Joseph Schumpeter introduziu no século XX a perspectiva do empreendedor como aquele que desafia ou destrói criativamente (FERNANDES E SANTOS, 2008). $\mathrm{Na}$ visão de Schumpeter, celebrizada na expressão "destruição criativa", o empreendedor é criativo, é a força motora do capital (HOELTGEBAUM et al, 2003).

Somente no final da década de 1970 o empreendorismo ganhou o status de disciplina (Palma, Cunha \& Lopes, 2007). Foi o francês Gifford Pinchot III quem designou, pela primeira vez, a expressão intraempreendedorismo (em inglês, intrapreneuring), para nomear o responsável pela inovação na organização, seja qual for o seu tipo, lugar ou momento. 
$\mathrm{Na}$ evolução do tema destacam-se as contribuições de Pryor e Shays (1993); Zahra (1996); Ted Nicholas (1993) e Wundebere (2001). Também merece atenção a sistematização de Cunningham e Licheron, focalizando o estudo do empreendedorismo desde a biografia dos seus estudiosos (escola bibliográfica), passando pela escola psicológica (abordagem comportamental), escola clássica (inovação sob a ótica da criação), escola de administração (empreendedorismo entendido como negócio), escola da liderança (o empreendedor age em grupo) e a escola corporativa, que enfatiza o ambiente das organizações, no qual o empreendedor deve se desenvolver.

O Manual de Oslo (2004) da Organização para a Cooperação e Desenvolvimento Econômico (OCDE), trata, no capítulo III, dos processos de inovação, identificando quatro tipos: de produto, de processo, organizacional e de marketing. O processo de inovação confere vantagens competitivas e de excelência às organizações. A literatura consagra essas e muitas outras formas de classificação das inovações, sendo a mais comum em produtos e processos. As inovações de processos são direcionadas por ideias e são mais intensivas nas economias menos desenvolvidas, referindo-se à adoção de métodos de produção novos ou aperfeiçoados. As inovações de produtos são impulsionadoras de novas tecnologias e são maiores e mais fortes nas economias desenvolvidas (Manual de Oslo, 2004). As inovações organizacionais envolvem as pessoas e o meio organizacional. Quando as inovações alcançam processos e métodos de marketing, o Manual de Oslo denomina "inovações de marketing". As inovações são também incrementais quando gradualmente introduzem avanços e melhorias nos métodos e produtos, bem como investimentos, de acordo com o tempo e as necessidades. Em contraponto, quando ocorrem abruptamente, são classificadas como radicais.

Do ponto de vista da amplitude, a inovação abrange qualquer setor da economia, inclusive os setores públicos, a exemplo da saúde e educação. Os diversos tipos de inovação se confundem e, por isso, é comum identificar mais de uma

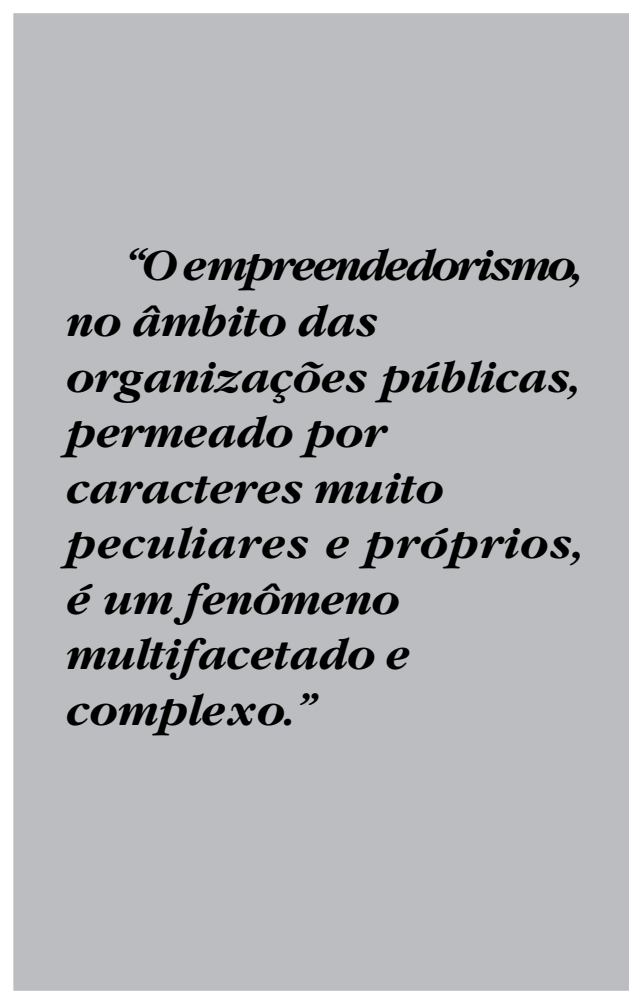

característica num mesmo processo. Assim uma inovação do tipo organizacional pode revelar também uma inovação de serviço e de marketing. Um processo de inovação de produto ou serviço pode representar também uma inovação organizacional. É ilustrativo mencionar que também ocorre combinação e/ou identificação de características comuns quanto aos processos de 
inovação; são os modelos denominados lineares (orientados pelas teorias clássicas e mecanicistas), "a partir de variáveis endógenas às empresas e como produto de seus processos internos", e os modelos interativos (orientados pelas teorias neoclássicas e que admitem forças externas), "que tentam incorporar as forças externas e atribuir a mudança técnica a fatores" (apud CONDE \& ARAUJO JORGE, 2003).

Nas organizações, sejam públicas ou privadas, com ou sem fins lucrativos, o intraempreendedor é o agente da inovação. Ele a busca e a conduz $\mathrm{O}$ protagonista da inovação é o intraempreendedor (PINCHOT, 1989; DORNELAS, 2003).

As forças que regem a inovação não diferem se o fenômeno do empreendedorismo ocorre numa organização privada ou pública. Os princípios regedores são os mesmos. Não importa que o processo seja conduzido por uma instituição governamental ou não governamental: basicamente as forças estão situadas entre o que funciona e o que não funciona.

\section{O empreendedorismo nas organi- zações (intraempreendedorismo)}

As perspectivas e trabalhos difundidos pelos estudiosos do empreendedorismo, como Peter Drucker, revolucionaram o pensamento da administração. $\mathrm{O}$ aprendizado, o conhecimento do espírito empreendedor nas organizações - intraempreendedorismo - constitui um diferencial, uma ferramenta essencial para enfrentar as constantes e profundas mudanças socioeconômicas e tecnológicas $\mathrm{da}$ atualidade, separando, inclusive, o empreendedor do administrador, pela prática da inovação bem-sucedida. Assim não deve ser confundido com o administrador. O empreendedor não se restringe ao que deve ser feito. Ele se incumbe muito além dos encargos designados para o administrador (DORNELAS, 2003).

Peter Drucker separa as organizações em três grupos - a empresa em atividade, a instituição de serviço público e a nova empresa de risco - e prescreve para cada uma delas uma maneira peculiar para a prática do empreendimento. Ou seja, para o autor existe uma "administração empreendedora" (também chamada de competência empreendedora) que se traduz num manual "para enfrentar cada caso, dificuldades, obstáculos e restrições na empresa privada, nova empresa (empresa de risco) ou organização pública" (DRUCKER, 1986).

O autor aponta sete fontes da experiência inovadora - quatro no ambiente interno das organizações (públicas ou privadas): o inesperado, a incongruência, a inovação baseada na necessidade de processo e mudanças na estrutura do setor ou do mercado. As demais, no ambiente externo das organizações (públicas ou privadas): as mudanças demográficas ou populacionais, as mudanças de percepção e significado e um novo conhecimento, científico ou não (idem, ibidem).

Incerteza, discrição, intuição, ação, dedicação, determinação, lealdade, jogo de cintura, sonhos são elencados no rol dos dez mandamentos do intrapreneur (РINCHOT, 2003). São conceitos e atributos que, em regra, diferenciam o intraempreendedor do administrador e do gerente tradicional.

Nas organizações, o intraempreendedor é mais do que criativo. Ele vai além de promover relações, superando dificuldades e fazendo as coisas ocorrerem. (FILION \& DOLABELA, 2000).

O intraempreendedor também se manifesta na criação e expansão de novos postos de trabalho e atividades nas organizações (COZzi et al, 2008). 
O empreendedorismo é vital na vida social e na economia, tanto nas organizações públicas quanto nas privadas, precisamente porque a inovação e o empreendimento não constituem "algo radical", mas "um passo de cada vez", um produto aqui, uma diretriz lá, um serviço público acolá (PETER DRUCKER, 2008).

Peter Drucker separa as organizações em três grupos: a empresa em atividade, a instituição de serviço público e a nova empresa de risco, e prescreve para cada um deles uma maneira peculiar - como diz um guia específico - para a prática do empreendimento. Ou seja, para o autor existe uma "administração empreendedora" (também chamada de competência empreendedora) que se traduz num verdadeiro manual para enfrentar cada caso, dificuldades, obstáculos e restrições no âmbito da empresa privada, nova empresa (empresa de risco) ou organização pública (DRUCKER, 1986).

O sociólogo e cientista político Thoenig (2007), ao diferenciar a dimensão pública da dimensão privada aponta que, na primeira, prevalecem as injunções políticas ("arena política"), a submissão ao orçamento público e que o processo de decisão é determinado pelo governo, e, não, pelo mercado. Ele afirma que a organização pública, diferentemente da privada, responde a não apenas uma, mas duas funções de produção. Enquanto a organização privada restringe-se à função de produção operacional, a organização pública desenvolve, além da operacional, a função de efetividade. Esta - denominada mudança societal - não encontra correspondência nas empresas e associações voluntárias. Thoenig (2007) explica:

"Não obstante, e isto é que faz toda a diferença, a administração organizacional do setor público deve levar em conta uma segunda função de produção, o que as organizações privadas não precisam. Essa função é chamada efetividade. Não é interna à instituição, mas, sim, externa. Está inserida num tecido social de algum gênero. [...] Num mesmo país pode haver diferenças significativas entre agências públicas. Algumas operam como se fossem empresas privadas, definindo suas próprias metas e critérios de eficiência, sem ter de prestar contas de qualquer função de efetividade. Outras têm de fato de prestar contas de ambas as funções de produção. Presume-se que devam ser eficientes sem deixar de ser efetivas."

Assumir risco, não temer demissão, inovação, revolução de ideias, mudanças, alternativas, resoluções, promover relações e agregar conhecimentos são desafios do cotidiano e da ação do intraempreendedor (DAL'BÓ, 2008; PINCHOT, 2003; FILION \& DOLABELA, 2000).

\section{O intraempreendedorismo nas organizações públicas}

O empreendedorismo na gestão pública pode ser caracterizado pelo modelo incremental, pois se traduz em melhoria paulatina de métodos e procedimentos administrativos; em outras palavras, pode ser constatado por meio do aumento da efetividade.

De acordo com Drucker, uma administração empreendedora se traduz no âmbito das agências públicas por meio da capacidade de se implementar mudanças significativas na organização interna do trabalho e, com isso, melhorar a oferta de serviços.

Em suma, o empreendedorismo pode estar presente em qualquer lugar, processo, meio, posição, independentemente de 
serem privadas ou públicas as organizações (SHUMPETER, 1949). No que diz respeito às públicas, são reconhecidas as suas peculiaridades (hierarquia excessiva, descontinuidade, paternalismo, burocracia, clientelismo, inflexibilidade), mas isso não as torna intangíveis ao empreendedorismo.

As forças que regem a inovação não diferem se o fenômeno do empreendedorismo ocorre numa organização privada ou pública. Os princípios regedores são os mesmos - não importa que o processo seja conduzido por uma instituição governamental ou não governamental: basicamente tal força está situada entre o que funciona e o que não funciona.

"As instituições do serviço público buscam maximizar e não otimizar" (DruCKer, 1986, p.245). O autor atribui tal característica a uma maneira, entre outras, de se compensar a ausência de lucros, qual seja: o empreendedor da organização pública busca crescer e ampliar sua área de atuação - crescer cada vez mais. As chamadas organizações públicas ou sociais enfrentam limites para a atuação empreendedora e pontos de resistência à ação inovadora que, na maioria das vezes, se impõe de fora para dentro e por pessoas estranhas ao ambiente organizacional ou, simplesmente, elas ocorrem em razão de crises ou catástrofes (DRUCKER, 1986).

É possível identificar nas organizações públicas brasileiras dificuldades relacionadas à inovação? Quais as soluções?

Dal'bó (2008) chama a atenção para o deficiente debate do empreendedorismo nas organizações públicas: "De forma especial, são relegadas a planos de menor importância à análise da ação intraempreendedora nas instituições públicas, por ser uma realidade ainda incipiente".
Matias-Pereira (2008, p.242) fala que o "esforço para criar uma cultura empreendedora na administração pública se apresenta como um fator-chave para a elevação da gestão pública no Brasil. [...] Isso exige que tanto a instituição como o servidor público tenham uma postura mais flexível, criativa e empreendedora".

Observa-se estudos e divulgação de ideias no sentido de transplantar para as organizações públicas experiências bemsucedidas no mundo privado.

A literatura, nesse particular, é pouco sistematizada e evidencia poucas diferenças nos processos de inovação, sejam os que ocorrem nas organizações privadas, sejam os que acontecem nas instituições públicas e, ainda, na seara das organizações sociais.

A ação intraempreendedora nas organizações públicas brasileiras passa pela iniciativa do Ministério do Planejamento (MP) por meio da Escola Nacional de Administração Pública (ENAP), que promove, há 15 anos, concurso para premiar experiências de inovação na gestão pública. O panorama geral dos premiados revela que, apesar dos alegados entraves e limitações, o intraempreendedorismo se faz presente. Do primeiro concurso Inovação na Gestão Pública Federal (1995) até o atual em andamento (2010), 1.309 inscrições foram recebidas e 301 práticas inovadoras nas instituições públicas foram premiadas; muitas delas, mais de uma vez, como é o caso do INSS - presente em mais da metade das premiações.

\section{Metodologia}

O Instituto Nacional do Seguro Social é a organização pública escolhida para ser o objeto de estudo da presente pesquisa, haja vista sua representatividade no estudo de caso do intraempreendedorismo, atestada pela 
regularidade de suas premiações no Concurso Inovação e, sobretudo, pela amplitude e diversidade de sua atuação.

A pesquisa foi realizada por meio de metodologia qualitativa, exploratória e adotando a estratégia de investigação do estudo de caso (CRESWell, 2007). Antecede o método qualitativo escolhido - estudo de caso - uma revisão de literatura com objetivo de identificar o que se encontrava disponível em livros, artigos, teses e, inclusive, experiências sobre o tema de pesquisa.

A revisão de literatura, além de buscar o embasamento teórico, estabeleceu uma comparação de estudos e métodos, apontando as lacunas existentes.

Quanto aos procedimentos (ANDRADE, 2008), a pesquisa documental indireta também abrange dados, estatísticas e informações obtidas no sítio da ENAP, no menu "Concurso Inovação na Gestão Pública Federal". A pesquisa utilizou dados secundários como os critérios de avaliação do concurso e relatórios/documentos fornecidos pela instituição previdenciária. Os critérios de avaliação para seleção das experiências inovadoras foram norteadores da entrevista semiestruturada.

Os dados da pesquisa documental primária foram obtidos pela pesquisa de campo. A coleta de dados foi realizada por meio da entrevista semiestruturada, aplicada aos integrantes das equipes e responsáveis pela gestão inovadora em questão, servidor ou não servidor (titulares de cargos temporários ou comissionados do INSS ou de qualquer outro órgão da área previdenciária), premiados pelo Concurso Inovação promovido pela ENAP.

A entrevista semiestruturada foi aplicada, majoritariamente, aos servidores integrantes de três equipes que foram premiadas pelo concurso: denominamos casos A, B e C. O estudo de caso A está relacionado ao atendimento programado do Instituto Nacional do Seguro Social; o B, ao Audprev: Sistema de Auditoria Previdenciária; e o C, ao Censo previdenciário: soluções inovadoras para atualização cadastral.

\section{Detalhamento dos procedimentos metodológicos}

Para cada caso selecionado foi realizada, pelo menos, uma entrevista. Somando os

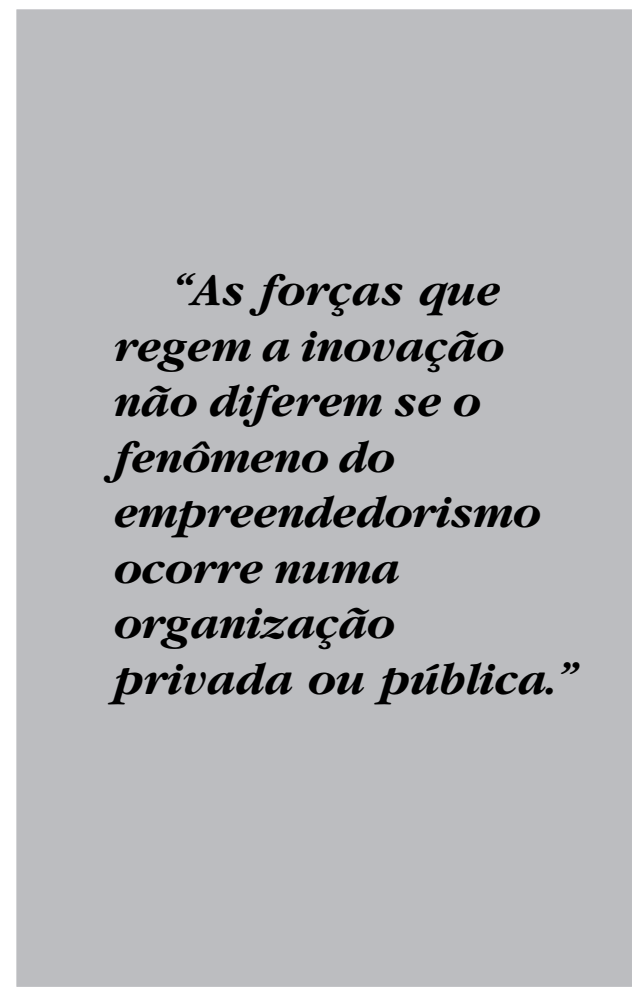

três casos, foram entrevistados quatro servidores. No caso A, uma servidora não ocupante de chefia e não diretamente ligada à equipe premiada. No caso $\mathrm{B}$, um servidor membro da equipe premiada; e no caso C, dois servidores integrantes da equipe premiada.

No caso A - Atendimento Programado do Instituto Nacional do Seguro Social - foi aplicado o instrumento de entrevista 
semiestruturada à servidora em exercício numa das unidades de atendimento do INSS. A servidora não participou da equipe de implementação do serviço e não exerceu função de coordenadora, tampouco de chefia. A inovação por processo, marketing e organizacional se identifica com a experiência. Quanto à amplitude, é semirradical. Segundo dados coletados, tanto na entrevista quanto nos dados secundários (documentos recolhidos no sítio da ENAP e no INSS), o processo foi desencadeado por fatores externos (modelo interativo). A inovação partiu dos escalões superiores (top down) e, por isso, foi relatada como dificuldade de implantação a resistência às mudanças na cultura organizacional. As soluções adotadas nesse caso foram: mídia, treinamento e adoção de novos métodos operacionais e tecnologias.

No caso B - Audprev: Sistema de Auditoria Previdenciária - foi aplicado o instrumento de entrevista semiestruturada ao servidor que apresentou a ideia inovadora. O servidor não exerceu função coordenadora, nem de chefia. A inovação por processo e organizacional se identifica com a experiência. Quanto à amplitude, é incremental e semirradical. Segundo dados coletados, tanto na entrevista quanto nos dados secundários, a experiência surgiu a partir de variáveis endógenas à organização e como produto de seus processos internos (modelo linear), bem como ocorreram influências de fatores externos (modelo interativo). A inovação surgiu nos escalões inferiores (bottom up). Como dificuldades foram apontadas: falhas dos sistemas operacionais, falta de continuidade e resistência às mudanças na cultura organizacional. As soluções adotadas para esse caso foram: mídia, treinamento e adoção de novos métodos operacionais e tecnologias.
No caso C - Censo previdenciário: soluções inovadoras para atualização cadastral - foi aplicado o instrumento de entrevista semiestruturada a dois servidores integrantes da equipe que estruturou e implementou o serviço.

Nesse caso, os servidores entrevistados não exerceram, nem exercem funções de chefia. A inovação por processo e organizacional se identifica com a experiência. Quanto à amplitude é incremental e semi-radical. Segundo dados coletados, tanto na entrevista como nos dados secundários (documentos recolhidos no sítio e na organização), a experiência surgiu a partir de variáveis endógenas e exógenas à organização e, assim, surgiu como produto de seus processos internos (modelo linear), bem como por influências de fatores externos (modelo interativo). A inovação surgiu nos escalões superiores (bottom up). A ação intraempreendedora surgiu a partir de uma crise da instituição. Foi determinada por agente externo (uma lei). Nas dificuldades relatadas foram apontadas falhas dos sistemas operacionais, falta de continuidade e resistências às mudanças na cultura organizacional. Soluções adotadas: mídia, treinamento e adoção de novos métodos operacionais e tecnologias.

\section{Resultados}

As premiações conferidas ao INSS pelo concurso Inovação na Gestão Pública Federal são o recorte empírico deste artigo. A partir da seleção de três exemplos de iniciativas inovadoras foram investigados as dificuldades, limites e soluções adotadas na ação intraempreendedora.

$\mathrm{Na}$ instituição previdenciária, os três casos selecionados foram: caso A $-13^{\circ}$ Concurso Inovação na Gestão Pública Federal, 
obtendo o $2^{\circ}$ lugar -, atendimento programado do Instituto Nacional do Seguro Social (INSS). Criado como instrumento de melhoria da qualidade, traduz a nova concepção do governo, que visualiza o cidadão como cliente prioritário. A criação em agosto de 2005 da Diretoria de Atendimento do INSS teve por objetivo, além de racionalizar o atendimento presencial, promover a redução das filas nas agências da previdência social em todo país e, especialmente, ampliar os meios de atendimento remoto da clientela de segurados. O novo serviço de atendimento programado proporcionou ao cidadão a ampliação de serviços como o de teleatendimento, com a criação de mais vagas e a consequente redução do tempo de espera nas agências, bem como aumentou a cesta de serviços ofertados. Os serviços no âmbito previdenciário público passaram a contar com a gestão das vagas disponibilizadas e a utilização mais racional da força de trabalho; oxigenando a estrutura funcional, facilitando decisões estratégicas e permitindo ao INSS implementar ações coincidentes com os anseios do cidadão segurado.

Caso B - $10^{\circ}$ Concurso Inovação na Gestão Pública Federal, obtendo o $4^{\circ}$ lugar -, Audprev: Sistema de Auditoria Previdenciária. A iniciativa surgiu de servidores com dificuldades em auditar grandes contribuintes da previdência social, em razão da inexistência de critérios lógicos de fiscalização. Esses decidiram criar uma espécie de passo a passo, com base na legislação previdenciária, a ser seguido pelos auditores fiscais em âmbito nacional, garantindo assim tratamento uniforme a todos os contribuintes, capaz de propiciar a racionalização e a excelência do setor.

A inovação envolveu processos e métodos com a implementação de um novo paradigma da ação de fiscalização objetivando a qualidade dos procedimentos das auditorias-fiscais e a melhoria da gestão tributária - previdenciária.

Caso C $-12^{\circ}$ Concurso Inovação na Gestão Pública Federal, obtendo também o $4^{\circ}$ lugar-, Censo previdenciário: soluções inovadoras para atualização cadastral. A inovação surgiu das dificuldades em atualizar o cadastro de 17,2 milhões de beneficiários da previdência social. As inconsistências dos dados cadastrais prejudicavam o controle da correta manutenção dos pagamentos de benefícios. O projeto possibilitou atualizar a base de dados e representou uma grande economia para a instituição. Além disso, promoveu condições mais confiáveis no que diz respeito à comprovação de vida dos beneficiários, possibilitando assim maior controle e melhor combate às fraudes. Foram apontados como fatores de sucesso: uma ampla rede de atendimento, a introdução de parcerias, a valorização dos servidores e, acima de tudo, a preocupação com a qualidade do atendimento, construindo um processo que se ajustasse às necessidades dos beneficiários, e, não, o contrário.

A Tabela 1 a seguir resume a análise do processo de inovação nos três casos. Os indicadores do quadro foram levantados pela revisão da literatura sobre o assunto nas organizações, sejam privadas ou públicas.

Como se trata do estudo de caso de intraempreendedorismo numa organização pública, foram utilizados indicadores do processo de decisão das políticas públicas.

A tabela analisa os dados obtidos a partir das entrevistas e, como fonte secundária, os dados colhidos no sítio da ENAP e nos documentos fornecidos pelos próprios entrevistados, os quais instruem os casos premiados. 
Tabela 1: O processo de inovação

\begin{tabular}{lllll}
\hline $\begin{array}{l}\text { Intraempreendedorismo } \\
\text { (processo de inovação) }\end{array}$ & Classificação & $\begin{array}{l}\text { Origem da } \\
\text { Ideia }\end{array}$ & Decisão & Amplitude \\
\hline Caso A & Processo Organizacional & Externo & Top down & Semirradical \\
\hline Caso B & Processo Organizacional & Interno & Bottom up & Semirradical \\
\hline Caso C & Processo Organizacional & Externo & Bottom up & Semirradical \\
\hline
\end{tabular}

Para responder à questão de pesquisa quantos aos limites e dificuldades, assim como as soluções adotadas para enfrentálos, apresentamos a Tabela 2.

Os indicadores foram identificados a partir das ações desenvolvidas na concepção, desenvolvimento e implementação da inovação e da forma como solucionaram as dificuldades encontradas.

A tabela a seguir representa o resumo da análise dos dados sobre as principais características dos três casos estudados quanto às dificuldades e soluções.

\section{Conclusão}

A conclusão a que a pesquisa nos leva é que, apesar dos alegados entraves e limitações, o intraempreendedorismo se faz presente nas organizações públicas e vem crescentemente sendo adotado pelas chefias ou por funcionários sem nenhum tipo de função comissionada, como relatado no caso B - Audprev: Sistema de Auditoria Previdenciária.

A inovação nas organizações públicas, representada pelo intraempreendedorismo

\section{Tabela 2: Características}

\begin{tabular}{lll}
\hline Intraempreendedorismo & Dificuldades & Soluções \\
\hline Caso A & Tecnológica & Mídia \\
& Metodológica & Treinamento \\
& Cultural & Inovação Tecnológica \\
& & Estrutural \\
\hline Caso B & Tecnológica & Mídia \\
& Metodológica & Treinamento \\
& Descontinuidade & Inovação Tecnológica \\
& Inflexibilidade & Estrutural \\
\hline Caso C & Tecnológica & Mídia \\
& Metodológica & Treinamento \\
& Descontinuidade & Inovação Tecnológica \\
& Cultural & Estrutural \\
\hline
\end{tabular}

Fonte: resultados da pesquisa 
das experiências premiadas pelo Concurso Inovação na Gestão Pública Federal, confirma nosso quadro teórico na medida em que se faz presente em diversos tipos de organização, em todos os seus processos e meios.

A análise dos casos revela que a ação intraempreendedora pode ocorrer nos diversos escalões ou segmentos hierárquicos da organização. Além disso, tanto os fatores endógenos (produto de seus processos internos) quanto exógenos (produto de fatores externos) são determinantes desse tipo de processo.

Importante ressaltar os dados obtidos e coligidos na Tabela 2, demonstrando que as dificuldades de caráter tecnológico, cultural e metodológico permearam os casos analisados e que as soluções devem se encaminhar para aspectos comunicacionais, culturais e estruturais. A pesquisa obteve o quadro das dificuldades que comumente são alegadas para obstar a prática do intraempreendedorismo nas organizações públicas e, ao mesmo tempo, demonstrou que as soluções foram encontradas, inovando métodos, tecnologias, processos e até mesmo transformando a cultura organizacional. Outro aspecto a ser considerado foi a ação de escalões inferiores na introdução e/ou proposição de ações inovadoras; em dois dos três casos analisados, o processo decisório teve influência ou foi desencadeado por funcionários que não pertenciam ao topo da hierarquia.

Nos próximos estudos, para aperfeiçoamento da pesquisa, deverão ser acrescentadas outras variáveis para análise das dificuldades e uma coleta de dados específica. $\mathrm{O}$ quadro de soluções também exige uma análise própria. A revisão de literatura deverá aprofundar o exame do estudo da inovação organizacional e do intraempreendedorismo, sobretudo nas instituições públicas.

(Artigo recebido em novembro de 2009. Versão final em setembro de 2010). 


\section{Referências bibliográficas}

Andrade, Maria Margarida de. Como preparar trabalhos para cursos de pós-graduação: noções práticas. São Paulo: Atlas, 2008.

Banco De Soluções. Escola Nacional de Administração Pública (2010). Disponível em:http: / / inovacao.enap.gov.br/index.php?option $=$ com_docman\&task $=$ cat_ view\&gid=13\&Itemid=32. Asseco em: 16 de julho de 2010 .

COnde, Mariza Velloso Fernandez;Araujo-jorge, Tânia Cremonini de. Modelos e concep̧̧ões de inovação: a transição de paradigmas, a reforma da C\&T brasileira e as concepções de gestores de uma instituição pública de pesquisa em saúde. São Paulo, v.8, n.3, 2003. Disponível em: <www.scielo.br/scielo.php?script=sci_arttext\&pid=S141381232003000300007\&lng=en\&nrm=iso >. Acesso em: 29 novembro 2008.

Cozzi, Afonso Otávio;judice, Valéria; Dolabela, Fernando;filion, Louis Jacques. Empreendedorismo de Base Tecnológica. Rio de Janeiro: Elsevier, 2008.

CReswell, John W. Projeto de pesquisa: métodos qualitativo, quantitativo e misto. Porto Alegre: Artmede, 2007.

DAL'BÓ, Reinaldo André. In: O intraempreendedor como agente de mudança: inovação e benefícios. Trabalho aceito para apresentação no SIMTEC - Simpósio de Profissionais da Unicamp/Campinas, de 29 set. a $1^{\circ}$ out. 2008.

DORnelas, José Carlos Assis. Empreendedorismo Corporativo: como ser empreendedor, inovar e se diferenciar em organizações estabelecidas. Rio de Janeiro: Elsevier, 2003. DRUCKer, Peter Ferdinand. Inovação e Espírito Empreendedor - prática e princípios. São Paulo: Cengage Learning, 2008.

Fernandes, Daniel Von; Der Heyde \&santos; Cristianne Pizzuti. Orientação empreendedora: um estudo sobre as conseqüências do empreendedorismo nas organizações. Revista RAE-eletrônica, São Paulo, v.7, n.1, Art. 6, jan./jun. 2008.

FIlion, Louis Jacques \&dolabela, Fernando. Boa Idéia! E agora? - Plano de Negócio, o caminho seguro para criar e gerenciar sua empresa. São Paulo: Cultura, 2000.

НАSнімото, Marcos. Espirito empreendedor nas organizações: aumentando a competitividade através do intra-empreendedorismo. São Paulo: Saraiva, 2006.

hoeltgebaum, M.; Perfeito, Juarez; DALFOvo, M. S.;LANA, R. A. A relação entre as estratégias traçadas na criação e desenvolvimento do empreendimento e o perfil empreendedor do dirigente proprietário: o caso de uma empresa de confecção de Brusque, SC, Brasil. In: Francisco Morea; Mariel Fornoni. (Org.). La formación de emprendedores como clave para el desarrollo. Mar del Plata (Argentina): Ediciones Soarez, 2006, v. 1, p. 101-118.

MORAEs, Juliana Girão de (Org.). Ações premiadas no $10^{\circ}$ Concurso Inovação na Gestão Pública Federal-2005. Brasília: ENAP, 2005. Disponível em: www.enap.gov.br/ index.php?option $=$ com_docman\&task $=$ cat_view \&gid $=745 \&$ dir $=$ ASC \& order $=$ name $\&$ limit $=5 \&$ limitstart $=0$. Acesso em: 16 de julho de 2010 . 
moraes, Juliana Girão de (Org.). Ações premiadas no $12^{\circ}$ Concurso Inovação na Gestão Pública Federal-2007. Brasília: ENAP, 2008. Disponível em: www.enap.gov.br/ index.php?option $=$ com_docman\&task $=$ cat_view \&gid $=745 \&$ dir $=$ ASC \& order $=$ name\&limit $=5 \&$ limitstart $=0$. Acesso em: 16 de julho de 2010 .

MORAEs, Juliana Girão de (Org.). Ações premiadas no13 Concurso Inovação na Gestão Pública Federal-2008. Brasília: ENAP, 2009. Disponível em: www.enap.gov.br/ index.php?option $=$ com_docman\&task $=$ cat_view \&gid $=745 \&$ dir $=$ ASC $\&$ order $=$ name $\&$ limit $=5 \&$ limitstart $=0$. Acesso em: 16 de julho de 2010 .

Lei $\mathrm{n}^{\circ}$ 10.973, de 2 de dezembro de 2004 - Lei da Inovação. Disponível em: http:/ / www.planalto.gov.br/ccivil_03/_ato2004-2006/2004/Lei/L10.973.htm. Acesso em: 29 de novembro de 2008.

matias, José Pereira. Curso de administração pública: foco nas instituições e ações governamentais. São Paulo: Atlas, 2008.

Manual de Oslo, desenvolvido pela Organização para Cooperação Econômica e Desenvolvimento (OCDE) e publicado no Brasil pela Financiadora de Estudos e Projetos (FINEP). Disponível em: www.finep.gov.br/dcom/brasil_inovador/menu.html. Acesso em: 16 de julho de 2010.

palma, Patrícia Jardim; cunha, Miguel Pina \& Lopes, Miguel Pereira. Comportamento Organizacional Positivo e Empreendedorismo: Uma influência mutuamente vantajosa. In: Comportamento Organizacional e Gestão, 2007, vol.13, n.1, p. 93-114.

PINCHOT III, Gifford. Intrapreneuring - Por que você não precisa deixar a empresa para tornar-se um empreendedor. São Paulo: Harbra Ltda, 1989.

PIRES, José Calixto de Souza \& MACÊDO, Kátia Barbosa. In: Cultura organizacional em organizações públicas no Brasil. Revista de Administração Pública, Rio de Janeiro, p. 81-105, jan./fev. 2006.

SHumpeter, Joseph A. Economic Theory and Entrepreneurial History, 1949, Change and the Entrepreneur. In: Revista Brasileira de Inovação, São Paulo, vol. I, n 2, jul./dez. 2002.

Essays on entrepreneurs, innovations, business cycles, and the evolution of capitalism. New Jersey: Transaction Publishers, 2006.

Business Cycles - A Theoretical, Historical and Statistical Analysis of the Capitalist Process. New York Toronto London: McGraw-Hill Book Company, 1939.

Capitalism, Socialism and Democracy. New York: Harper Collins Publishers, 2008.

THOENIG, Jean Claude. In: Recuperando a ênfase na dimensão pública dos estudos organizacionais. Trabalho originalmente apresentado no encontro Egos - Laemos, em Puebla, México, jan. 2006. Revista de Administração Pública, Rio de Janeiro, Edição Especial Comemorativa, p. 09-36.

vogel, J.P. In: O Intraeemprendedorismo na Prática. Ix Congreso Internacional Del Clad Sobre La Reforma Del Estado y De La Administración Pública, 2 - 5 nov. 2004, Madrid, España. 


\section{Resumo-Resumen-Abstract}

\section{Intraempreendedorismo e a inovação na gestão pública federal} Meire Lúcia Gomes Monteiro Mota Coelho

O objetivo deste artigo é apresentar três ações empreendedoras em organizações públicas premiadas pela ENAP no concurso Inovação na Gestão Pública Federal. A partir da revisão de literatura e estudo de caso, serão confrontados os diversos tipos e modelos de processos de inovação, para identificar as dificuldades apontadas e as soluções adotadas nas ações premiadas. Foram selecionados três casos de iniciativas inovadoras no INSS, apontando a origem, características, amplitude e o modelo do processo. Nosso quadro teórico de referência está estruturado no sentido de aprofundar a percepção, bem como nos dar condições de comparar alguns estudos e apontar lacunas, se existentes. A pesquisa foi realizada por meio de metodologia qualitativa, exploratória e adotando a estratégia de investigação do estudo de caso. A revisão de literatura teve como objetivo identificar o que se encontra disponível em livros, artigos, teses e, inclusive, experiências. A conclusão alcançada no artigo é a de que, apesar dos alegados entraves e limitações, o intraempreendedorismo se faz presente nas organizações públicas e vem crescentemente sendo adotado pelas chefias ou mesmo por funcionários sem nenhum tipo de função comissionada, como relatado em um dos casos. A inovação nas organizações públicas, representada pelo intraempreendedorismo das experiências premiadas pelo concurso, confirma nosso quadro teórico na medida em que ações empreendedoras geradoras de inovação se fazem presentes nas organizações públicas, em todos os seus processos e meios. A análise dos casos nos revela ainda que a ação intraempreendedora pode ocorrer nos diversos escalões ou segmentos hierárquicos da organização. Além disso, tanto os fatores endógenos (produto de seus processos internos) quanto os exógenos (produto de fatores externos) são determinantes nesse processo.

Palavras-chave: Inovação na gestão pública; empreendedorismo; intraempreendedorismo.

\section{Intrapreneurship y la innovación en la gestión pública federal.}

Meire Lúcia Gomes Monteiro Mota Coelho

El objetivo de este artículo es presentar tres acciones emprendedoras en organizaciones públicas premiadas por la ENAP, en el concurso "Innovación en la Gestión Pública Federal". Partiendo de la revisión de literatura e de los estudios de caso, los diferentes tipos y modelos de procesos de innovación serán estudiados para identificar las dificultades encontradas y las soluciones adotadas en las acciones premiadas por el concurso. Fueron seleccionados tres casos de iniciativas innovadoras en el INSS, destacando el origen, características, amplitud y el modelo del proceso de innovación en sí mismo. Nuestro cuadro teórico está estructurado a fin de profundizar nuestra percepción, además de darnos condiciones de comparar algunos estudios e mostrar las lagunas, si existentes. La pesquisa fue realizada a través de metodología cualitativa y exploratoria, y de la adopción de estrategia investigativa del estudio de caso. La revisión de literatura tuvo como objetivo identificar lo que se encuentra disponible en libros, artículos, tesis y, incluso, experiencias. La conclusión lograda en este artículo es que, a pesar de los obstáculos y de las limitaciones, el intrapreneurship se hace presente en las organizaciones públicas y viene siendo cada vez más adoptado por los jefes o por los funcionarios sin ningún tipo de incentivo financiero, como es relatado en uno de los casos. La innovación en las organizaciones públicas, representada por el intrapreneurship de las experiencias premiadas por el concurso "Innovación en la Gestión Pública Federal", confirma nuestro cuadro teórico en la medida enque las acciones emprendedoras generan innovaciones que se hacen presentes en las organizaciones públicas, en todos los procesos y medios. El análisis de los casos nos revela también que la acción de intrapreneurship puede ocurrir en los vários escalones o segmentos jerárquicos de la organización. 
Además, ambos los factores endógenos (producto de los procesos interiores) y exógenos (producto de los factores externos) son determinantes en el proceso de innovación.

Palabras Clave: Iniciativa empresarial en las organizaciones públicas; acciones emprendedoras; innovación en la gestión pública.

\section{Entrepreneurship and innovation on federal public management}

Meire Lúcia Gomes Monteiro Mota Coelho

The purpose of this article is to present three entrepreneurship actions in public organization, awarded by ENAP, the "Innovation in Federal Public Management prize. From the literature review and case study, the several types and models of innovation processes will be confronted in order to identify the highlighted difficulties and the solutions adopted in the scenarios awarded by the contest. Three innovative experiences in the INSS were selected, pointing the origin, characteristics, amplitude and the model of innovation processes in itself. Our theoretical framework of reference is structured in a way to profound our perception as well as to provide the conditions to compare studies and to bring to light the gaps, if existing. The research has been developed through the qualitative and exploratory methodology, and adopting a investigative strategy of the case study. The literature review had as goal the identification of what is available in books, articles, thesis and, also, experiences. The conclusion reached in this article is that, in spite of the alleged obstacles and limitations, the intrapreneurship is present in public organizations and it has been being adopted by management positions and by civil servants without any kind of commissioned function, as reported in one of the cases. The innovation in the public organizations, represented by the intrapreneurship of the experiences awarded by the contest confirms our theoretical framework that entrepreneurship actions generating innovation are present in public organizations, in all of its processes and means. The analysis of the cases still reveals that the intrapreneurship action can occur in the many levels and hierarchical segments of the organization. Besides, the endogenous factors (product of its internal processes) as well as the exogenous (products of external factors) are determinants in this process.

Keywords: Innovation and entrepreneurship; intrapreneurship public organizations; innovation in public management.

Meire Lúcia Gomes Monteiro Mota Coelho

Procuradora Federal, conselheira federal da OAB e presidente da Comissão Nacional da Advocacia Pública da OAB Federal. Pós-graduada em Direito pela Universidade Federal do Piauí (UFPI) e em Administração Pública pela Fundação Getúlio Vargas (FGV/DF); mestranda em Administração pelo Centro Universitário UNIEURO. Palestrante em diversos seminários e congressos, especialmente nas áreas de Administração Pública e Previdenciária, além de ser autora, coautora e coordenadora de livros, artigos e pareceres especialmente na área previdenciária e de gestão pública. Contato: meiremotacoelho@gmail.com 
